\title{
Quantitative analysis of research trends in a leading ecological journal: bibliometric study during 2003-2012
}

\author{
Saravanan Govindaradjou ${ }^{1}$ \\ saravanan.g@ifpindia.org \\ ORCID Id.: https://orcid.org/0000-0001-7040-0622 \\ Dominic John ${ }^{2}$ \\ jdom16@gmail.com \\ ORCID Id.: http://orcid.org/0000-0002-6039-641X
}

\begin{abstract}
Received: 15 March 2014
Accepted: 22 June 2014

The journal Ecology is one of the premier journals in the field of ecology, published by the Ecological Society of America. Ten volumes of the journal containing 120 issues from 2003 to 2012 have been taken into consideration for the present study that carries out a bibliometric analysis of the 3,359 papers and 164,369 references of this journal. The analysis covers parameters like growth pattern, authorship pattern and author productivity, with most productive countries and institutions. Out of 3,359 contributions, only 410 were single-authored and the rest were multi-authored with a Collaboration Coefficient of 0.21. Applicability of Lotka's Law has been tested. The most productive institution was the University of California at Davis, with 183 publications. The United States of America topped the list of countries with 2,188 papers, while South Africa occupied eighteenth position.
\end{abstract}

Keywords: Ecology, bibliometrics, authorship pattern, mapping, VOSviewer, h-index, impact factor, South Africa

\section{Introduction}

Ecology is the scientific study concerned with the relationship between organisms and their past, present, and future environments. These relationships include the physiological responses of individuals, the structure and dynamics of populations, the interactions among species, the organisation of biological communities, and the processing of energy and matter in ecosystems. Unlike many other disciplines, in ecology the issues are similar across the world, encouraging comparative studies and the participation of an international community of researchers.

Bibliometrics (biblion meaning "book" and metricus meaning "measurement") is a quantitative method of study concerned primarily with the analysis and description of literature. Its task, immodestly enough, is to provide evolutionary models of science, technology, and scholarship (Egghe 1988: 179). Pritchard (1969: 348) states that bibliometrics deals with the application of mathematics and statistical methods to books and other media of communication. Researchers may use these methods of evaluation to determine the influence of a single writer or to describe the relationship between two or more writers or their works. In the present study, an attempt has been made to study the publication trends in the field of ecology over a ten-year period, by using bibliometric analysis of a leading journal in the domain.

Ecology (ISSN 0012-9658) is a monthly journal published by the Ecological Society of America, Washington DC. Ecology publishes essays and articles that report and interpret the results of original scientific research in basic and applied ecology. The journal publishes a broad array of research in this rapidly-expanding field, covering techniques, approaches, and concepts.

\section{Literature review}

A considerable number of studies have been carried out to explore individual journal publications and literature on specific subject areas:

Liu, Kong and Duan (2011) analysed twelve Chinese mainstream ecological journals' publishing index, citation index and internet reach, and grouped the journals. They stressed that the Chinese ecological journals should make up a community - a digital journal aggregation. Prozesky and Boshoff (2012) attempted to analyse gender-related factors in research performance within the field of invasion ecology. Their investigation was based on journals included in the Thomson Reuters Web of Science from 1990 to 2002, focusing on South African science. Narang and Kumar (2010) conducted a bibliometric analysis of 4,798 citations appended to 400 articles in the Indian Journal of Pure and Applied Mathematics from 2003 to 2007. Results indicated a decrease in the number of contributions in successive volumes and that most citations were from journals. Mohamed, Nagarajan and Jothi (2011) discussed authorship trends and

1. Saravanan Govindaradjou is a librarian at the French Institute of Pondicherry, India, and a PhD scholar in the Department of Library and Information Science, Karpagam University, India.

2. Dominic John is the University Librarian, Karunya University, India. 
collaborative research in the field of agricultural extension in the Journal of Extension System during the period 20002009. The results showed that multi-authored papers outnumbered single-authored papers. Sevukan and Sharma (2008) presented a detailed analysis of research performances of biotechnology faculties in Central Universities of India from 1997 to 2006. The results indicated that twin-authored publications dominated and validated the applicability of Lotka's Law. However, the application of Bradford's Law did not fit in to the literature analysed. Thanuskodi and Venkatalakshmi (2010) studied the growth and development of research on ecology in India through Web of Science publications from 1990 to 2006. Their results indicated that $80 \%$ of contributions were multi-authored. Aswathy and Gopikuttan (2012) analysed 780 papers from five volumes in the Journal of Spacecraft and Rockets during 2006-2010, finding that, in terms of publications, the United States of America (USA) had the biggest share of papers. India occupied seventh position, with the most contributions coming from its universities.

\section{Objectives}

The primary objective of this study was to quantify and assess the research performance of the journal Ecology by analysing its publication output during a period of ten years (2003 to 2012) using bibliometric indicators. We also aimed to study the applicability of Lotka's Law. Other objectives were to explore the h-index, highly cited publications, the impact of cited references and journals, and various collaborative issues over the ten-year period.

\section{Method and materials}

The data presented in this paper have been retrieved from the Science Citation Index Expanded, accessed via Web of Science, published by Thomson Reuters. The keyword "ecology" has been used as the search term in the field of "publication name" and the time period was limited to 2003 to 2012 (ten years). 3,359 papers from Ecology were retrieved. Microsoft Office Excel and Microsoft Office Word were used to analyse the final data collected in order to generate tables, charts, and graphs.

\section{Data analysis and interpretation}

In this paper, various statistical techniques are used for our analysis.

A total of 3,359 papers were included in five document types during the ten-year study period, comprising 3,119 $(92.86 \%)$ articles and $147(4.38 \%)$ editorial pieces. Less significant, were fifty reviews $(1.49 \%)$, forty-two corrections $(1.25 \%)$ and one reprint $(0.03 \%)$.

\subsection{Growth of Ecology literature from 2003 to 2012}

During the period 2003-2012, the journal Ecology published 3,359 publications with an average of 279.92 publications per year. Fluctuations in publication patterns of ecology literature were noticed throughout the period of study. However, the highest number of publications was recorded in 2010 (387 papers; $11.52 \%$ of total publications in the ten-year period) while the lowest was in the year 2011 (240 papers; $7.14 \%$ of total publications in this period).

\subsection{Relative Growth Rate and Doubling Time of Publications}

Relative Growth Rate is the increase in the number of publications / pages per unit of time. The growth rate of total publications in Ecology has been calculated on the basis of Relative Growth Rate (RGR) and Doubling Time (DT) model developed by Mahapatra (1985). Mathematical representation of the mean Relative Growth Rate of articles over a specific period is derived by the following formula:

$R(P)=\frac{\log _{e} 2 P-\log _{e} 1 P}{2^{T}-1^{T}}$

Here $R(P)=$ Relative Growth Rate of articles over the specific period of time.

$\log _{\mathrm{e}} 1 \mathrm{P}=\mathrm{Log}$ of initial number of articles.

$\log _{\mathrm{e}} 2 \mathrm{P}=\mathrm{Log}$ of final number of articles.

$2^{T}-1^{\top}=$ The unit difference between the initial time and final times.

There exists a direct relationship between the Relative Growth Rate and Doubling Time. If the number of publications / pages of subject doubles during a given period, then the difference between the logarithms of the numbers at the beginning and at the end of the period must be the logarithms of the number 2 . If one uses natural logarithms, this difference has the value of 0.693 . Thus, the corresponding Doubling Time for publications and pages can be calculated by the following formula:

$$
\mathrm{DT}=\frac{\log _{\mathrm{e}} 2}{\mathrm{R}(\mathrm{P})}=\frac{0.693}{\mathrm{R}(\mathrm{P})}
$$


Here, DT(p) and DT(c) are the average Doubling Time for articles and citations respectively. The RGR and DT are used to express the nature of growth of knowledge. The Relative Growth Rate and Doubling Time of publications were derived and are presented in Table 1. It can be noticed that the Relative Growth Rate of publications decreased from 0.72 in 2004 to 0.09 in 2012. The mean relative growth for the first four years (2004 to 2007) was higher than during the last five years (2008 to 2012).

Table 1 Relative Growth Rate and Doubling Time of Ecology during 2003 to 2012

\begin{tabular}{|c|c|c|c|c|c|c|c|c|}
\hline Year & $\begin{array}{c}\text { No. of } \\
\text { papers }\end{array}$ & $\begin{array}{c}\text { Cumulative } \\
\text { no. of papers }\end{array}$ & $\log _{\mathrm{e}} 1^{\mathrm{p}}$ & $\log _{\mathrm{e}} 2^{p}$ & {$[R(P)]$} & $\begin{array}{l}\text { Mean } \\
{[R(P)]}\end{array}$ & {$[\mathrm{Dt}(\mathrm{P})]$} & Mean $[\mathrm{Dt}(\mathrm{P})]$ \\
\hline 2003 & 327 & 327 & & 5.79 & & & & \\
\hline 2004 & 348 & 675 & 5.79 & 6.51 & 0.72 & & 0.96 & \\
\hline 2005 & 357 & 1032 & 6.51 & 6.94 & 0.42 & & 1.63 & \\
\hline 2006 & 346 & 1378 & 6.94 & 7.23 & 0.29 & & 2.40 & \\
\hline 2007 & 336 & 1714 & 7.23 & 7.45 & 0.22 & 0.33 & 3.18 & 1.63 \\
\hline 2008 & 374 & 2088 & 7.45 & 7.64 & 0.20 & & 3.51 & \\
\hline 2009 & 352 & 2440 & 7.64 & 7.80 & 0.16 & & 4.45 & \\
\hline 2010 & 387 & 2827 & 7.80 & 7.95 & 0.15 & & 4.71 & \\
\hline 2011 & 240 & 3067 & 7.95 & 8.03 & 0.08 & & 8.50 & \\
\hline 2012 & 292 & 3359 & 8.03 & 8.12 & 0.09 & 0.13 & 7.62 & 5.76 \\
\hline
\end{tabular}

At the same time, the corresponding Doubling Time for different years gradually increased from 2004 to 2012 . The mean Doubling Time for the first four years (i.e. 2004 to 2007) was only 1.63 which increased to 7.62 during the last five years (2008 to 2012). As the rate of growth of publication decreased, the corresponding Doubling Time increased. It could be deduced that in general there is a progressive increase in the number of publications for the study period. However, the Relative Growth Rate shows a downward trend which means the rate of increase is proportionately low, and this is highlighted by the Doubling Time for publications, which is higher than the Relative Growth Rate.

The mean relative growth of ecology literature has shown a declining trend. Consequently, mean Doubling Time has increased. These trends may be due to the communication pattern of ecologists. Many ecological communications may not appear in the form of journal articles, the primary source of materials for the abstracting journals.

\subsection{Authorship pattern and Collaborative Coefficient}

It can be seen in Table 2 that most of the papers investigated were multi-authored (87\%).

Table 2 Distribution of Authorship pattern in Ecology during 2003 to 2012

\begin{tabular}{ccccccc}
\hline Year & Single & Two & $\begin{array}{c}\text { Multi } \\
\mathbf{( 3 - 6 )}\end{array}$ & $\begin{array}{c}\text { Mega } \\
\text { (More } \\
\text { than 7) }\end{array}$ & Total & $\begin{array}{c}\text { Collaborative } \\
\text { Coefficient }\end{array}$ \\
\hline 2003 & 62 & 108 & 146 & 12 & 328 & 0.14 \\
2004 & 60 & 116 & 163 & 9 & 348 & 0.16 \\
2005 & 38 & 112 & 191 & 16 & 357 & 0.24 \\
2006 & 44 & 104 & 178 & 20 & 346 & 0.21 \\
2007 & 50 & 91 & 168 & 26 & 335 & 0.18 \\
2008 & 45 & 94 & 200 & 35 & 374 & 0.21 \\
2009 & 30 & 95 & 198 & 29 & 352 & 0.26 \\
2010 & 50 & 102 & 201 & 34 & 387 & 0.20 \\
2011 & 12 & 49 & 157 & 22 & 240 & 0.30 \\
2012 & 19 & 66 & 181 & 26 & 292 & 0.28 \\
Total & 410 & 937 & 1783 & 229 & 3359 & 0.21 \\
Percentage & 12.21 & 27.90 & 53.08 & 6.82 & 100 & \\
\hline
\end{tabular}

Out of 3,359 papers, the highest number of papers was published by more than two authors (three to six authors): 1,783 in total (53.08\%). The trend in this journal shows a preference for collaborations which, in turn, is an indication of team research. In other words, collaborative research was predominant in the journal during the study period. The mathematical formula to calculate Collaborative Coefficient (Ajiferuke, Burrel \& Tague 1988) is: 


$$
C C=1-\frac{\sum_{j=1}^{A}(1 / j) f_{j}}{N},
$$

where $\mathrm{fj}$ is the number of $\mathrm{j}$-author papers published in a discipline during a certain period of time; $\mathrm{N}$ is the total number of papers published in a discipline during a certain period of time; and $\mathrm{j}$ is the greatest number of authors per paper in a discipline. Based on the data presented in Table 2, the Collaborative Coefficient (CC) was calculated .The calculated value of CC for the study period does not vary much over the years. The value of CC is lowest (0.14) for 2003 and highest $(0.30)$ for 2012. The CC usually will be between 0 and 1 ; if it is near 1 , it is assumed that the collaboration is high and if it is near 0 it indicates less collaboration. This again indicates that the researchers in the field of ecology during the study period have been fairly collaborative.

\subsection{Author productivity}

Lotka's Law (Lotka 1926) is one of the three classic laws of bibliometrics and deals with the frequency of publication by authors in any given field. The generalised form of Lotka's Law can be expressed as

$$
x^{n} y=k
$$

where $y$ is the number of authors with $x$ articles, the exponent $n$ and constant $k$ are parameters to be estimated from a given set of author productivity data.

The value of exponent $n$ is calculated by the least-squares method described by Pao (1985) using the following formula:

$$
n=\frac{\left[N \sum\left(\ln x \cdot \ln g(x)-\sum \ln g(x) \sum \ln x\right]\right.}{\left[N \sum(\ln x)^{2}-\left(\sum \ln x\right)^{2}\right]}, \text { where } \mathrm{N}=10 \text { (i.e. } \mathrm{n}=2.23 \text { ) }
$$

$N=$ number of pairs of data

$X=$ logarithm of $x$, i.e. number of articles

$Y=$ logarithm of $y$, i.e. number of authors

The value of $k$, which is the theoretical number of authors with a single article, is determined from the following formula:

\begin{tabular}{|c|c|c|c|c|c|c|c|c|c|c|}
\hline $\mathbf{x}$ & $y$ & $\begin{array}{c}X \\
(\log x)\end{array}$ & $\begin{array}{c}Y \\
(\log y)\end{array}$ & $x X$ & $X Y$ & Observed & $\begin{array}{c}\text { Cumulative } \\
\text { observed }\end{array}$ & Expect & $\begin{array}{c}\text { Cumulative } \\
\text { expected }\end{array}$ & D \\
\hline 1 & 5335 & 0.000 & 3.727 & 0.000 & 0.000 & 0.736 & 0.736 & 0.680 & 0.680 & 0.056 \\
\hline 2 & 1036 & 0.301 & 3.015 & 0.091 & 0.908 & 0.143 & 0.879 & 0.145 & 0.825 & 0.054 \\
\hline 3 & 392 & 0.477 & 2.593 & 0.228 & 1.237 & 0.054 & 0.933 & 0.059 & 0.884 & 0.049 \\
\hline 4 & 211 & 0.602 & 2.324 & 0.362 & 1.399 & 0.029 & 0.962 & 0.031 & 0.915 & 0.047 \\
\hline 5 & 101 & 0.699 & 2.004 & 0.489 & 1.401 & 0.014 & 0.976 & 0.019 & 0.933 & 0.042 \\
\hline 6 & 66 & 0.778 & 1.820 & 0.606 & 1.416 & 0.009 & 0.985 & 0.013 & 0.946 & 0.039 \\
\hline 7 & 33 & 0.845 & 1.519 & 0.714 & 1.283 & 0.005 & 0.989 & 0.009 & 0.955 & 0.035 \\
\hline 8 & 27 & 0.903 & 1.431 & 0.816 & 1.293 & 0.004 & 0.993 & 0.007 & 0.961 & 0.032 \\
\hline 9 & 21 & 0.954 & 1.322 & 0.911 & 1.262 & 0.003 & 0.996 & 0.005 & 0.966 & 0.030 \\
\hline 10 & 5 & 1.000 & 0.699 & 1.000 & 0.699 & 0.001 & 0.997 & 0.004 & 0.970 & 0.026 \\
\hline 11 & 6 & 1.041 & 0.778 & 1.084 & 0.810 & 0.001 & 0.997 & 0.003 & 0.974 & 0.024 \\
\hline 12 & 1 & 1.079 & 0.000 & 1.165 & 0.000 & 0.000 & 0.998 & 0.003 & 0.976 & 0.021 \\
\hline 13 & 4 & 1.114 & 0.602 & 1.241 & 0.671 & 0.001 & 0.998 & 0.002 & 0.978 & 0.020 \\
\hline 14 & 5 & 1.146 & 0.699 & 1.314 & 0.801 & 0.001 & 0.999 & 0.002 & 0.980 & 0.018 \\
\hline 15 & 3 & 1.176 & 0.477 & 1.383 & 0.561 & 0.000 & 0.999 & 0.002 & 0.982 & 0.017 \\
\hline 16 & 2 & 1.204 & 0.301 & 1.450 & 0.362 & 0.000 & 0.999 & 0.001 & 0.983 & 0.016 \\
\hline
\end{tabular}

$$
k=\frac{1}{\sum_{x=1}^{p-1} 1 / x^{n}+1 /(n-1)\left(p^{n-1}\right)+\frac{1}{2} p n+n / 24 \times(p-1)^{n+1}}
$$

Table 3 Application of Lotka's Law in Ecology during 2003 to 2012 


\begin{tabular}{ccccccccccc}
17 & 2 & 1.230 & 0.301 & 1.514 & 0.370 & 0.000 & 1.000 & 0.001 & 0.985 & 0.015 \\
20 & 1 & 1.301 & 0.000 & 1.693 & 0.000 & 0.000 & 1.000 & 0.001 & 0.985 & 0.014 \\
23 & 1 & 1.362 & 0.000 & 1.854 & 0.000 & 0.000 & 1.000 & 0.001 & 0.986 & 0.014 \\
Total & 7252 & 17.214 & 23.613 & 17.913 & 14.474 & & & & Max D & 0.056 \\
\hline
\end{tabular}

The productivity of the paper contribution of the journal Ecology was verified to be in conformity with Lotka's inverse square law using Pao's method, to know the values of $n$ and C.

Here $n$ is substituted with the value 2.23 and $k$ is calculated as 0.68 using the equation, while $p$ is assumed to be 20 . By replacing the values of $n$ and $k$, the difference is calculated (Table 3). Here $D$ is the minimum and hence the present data set is in conformity with Lotka's Law. From the table it is clear that the maximum absolute difference value $D_{\max }$ which represents the maximum deviation is identified as 0.056 . The table value or critical value of $D$ in the KolmogrovSmirnov (K-S) test at 0.05 level of significance is 0.016 . While the calculated value of $D, 0.056$, is less compared to the table value 0.019 , it is clear that the calculated value of $D$ falls within the critical value of $D$. Thus, the distribution of author productivity of the present data set confirms Lotka's Law.

\subsection{Prolific authors in Ecology}

Table 4 lists the most productive authors in the overall field of ecology and their $\mathrm{h}$-index values while Table $4 \mathrm{a}$ depicts prolific authors who have produced more than 13 papers in the journal Ecology during the period of study. Their $\mathrm{h}$-index values are also listed.

Table 4 Top Ten authors in the field of ecology

\begin{tabular}{|c|c|c|c|c|c|c|c|}
\hline Author & $\begin{array}{c}\text { No. of } \\
\text { contributions }\end{array}$ & $\begin{array}{l}\text { Sum of the } \\
\text { times Cited }\end{array}$ & $\begin{array}{l}\text { Sum of Times Cited } \\
\text { without self- } \\
\text { citations }\end{array}$ & $\begin{array}{l}\text { Citing } \\
\text { Articles }\end{array}$ & $\begin{array}{c}\text { Citing } \\
\text { articles } \\
\text { without } \\
\text { self- } \\
\text { citations }\end{array}$ & $\begin{array}{c}\text { Average } \\
\text { citations per } \\
\text { Item }\end{array}$ & $\begin{array}{c}\text { h- } \\
\text { index }\end{array}$ \\
\hline Shine, R. & 178 & 4581 & 4077 & 2813 & 2667 & 25.74 & 37 \\
\hline Luiselli, L. & 113 & 1226 & 895 & 725 & 626 & 10.85 & 19 \\
\hline Poulin, R. & 101 & 2679 & 2433 & 1700 & 1620 & 26.52 & 30 \\
\hline Baskin, C.C. & 100 & 1474 & 1285 & 1041 & 971 & 14.74 & 21 \\
\hline Baskin, J.M. & 98 & 1445 & 1258 & 1018 & 948 & 14.74 & 21 \\
\hline Macdonald, D.W. & 92 & 2791 & 2687 & 2345 & 2294 & 30.34 & 29 \\
\hline Gaston, K.J. & 85 & 3674 & 3563 & 3044 & 2990 & 43.22 & 36 \\
\hline Hobson, K.A. & 85 & 3641 & 3479 & 2502 & 2442 & 42.84 & 31 \\
\hline Stenseth, N.C. & 82 & 3951 & 3852 & 3231 & 3187 & 48.18 & 30 \\
\hline Cherel, Y. & 81 & 2158 & 1891 & 1394 & 1323 & 26.64 & 29 \\
\hline
\end{tabular}

Table 4a Most productive authors in the journal Ecology during 2003-2012

\begin{tabular}{lccccccc}
\hline \multicolumn{1}{c}{ Author } & No. of & $\begin{array}{c}\text { Sum of } \\
\text { the } \\
\text { times } \\
\text { contributions }\end{array}$ & $\begin{array}{c}\text { Sum of } \\
\text { times } \\
\text { cited } \\
\text { without } \\
\text { self- } \\
\text { citations }\end{array}$ & $\begin{array}{c}\text { Citing } \\
\text { articles }\end{array}$ & $\begin{array}{c}\text { Citing } \\
\text { articles } \\
\text { without } \\
\text { self- } \\
\text { citations }\end{array}$ & $\begin{array}{c}\text { Average } \\
\text { citations } \\
\text { per Item }\end{array}$ & $\begin{array}{c}\text { h-index } \\
\text { hed }\end{array}$ \\
\hline Agrawal, A.A. & 23 & 921 & 913 & 829 & 824 & 40.04 & 13 \\
Nichols, J.D. & 20 & 1251 & 1227 & 951 & 939 & 62.55 & 13 \\
Ives, A.R. & 17 & 408 & 403 & 392 & 389 & 24 & 10 \\
Royle, J.A. & 17 & 901 & 874 & 613 & 600 & 53 & 13 \\
Bertness, M.D. & 16 & 533 & 524 & 470 & 463 & 33.31 & 13 \\
Clark, J.S. & 16 & 980 & 962 & 854 & 846 & 61.25 & 10 \\
Callaway, R.M. & 15 & 1010 & 1001 & 884 & 878 & 67.33 & 13 \\
Legendre, P. & 15 & 1483 & 1464 & 1155 & 1146 & 98.87 & 13 \\
Shine, R. & 15 & 461 & 456 & 413 & 408 & 30.73 & 13 \\
Hines, J.E. & 14 & 761 & 746 & 660 & 652 & 54.36 & 10 \\
Jackson, R.B. & 14 & 1333 & 1329 & 1260 & 1257 & 95.21 & 11
\end{tabular}




\begin{tabular}{llllllcc} 
Reich, P.B. & 14 & 567 & 566 & 549 & 548 & 40.5 & 9 \\
Trussell, G.C. & 14 & 518 & 495 & 415 & 406 & 37 & 10 \\
Wright, S.J. & 14 & 797 & 780 & 660 & 651 & 56.93 & 12 \\
\hline
\end{tabular}

The h-index is an index that quantifies both the actual scientific productivity and the apparent scientific impact of a scientist. The index is based on the set of most-cited papers of a scientist and the number of citations that such a set of papers has received in other publications. Hirsch (2005) postulates that

A scientist has an index $\mathrm{h}$ if $\mathrm{h}$ of his or her Np papers has at least $\mathrm{h}$ citations each and the other $(\mathrm{Np}-$ $h)$ papers have less than $h$ citations each. The value of $h$ is equal to the number of papers $(N)$ in the list that have $\mathrm{N}$ or more citations.

To identify the h-index values of the prominent authors, we used the "create citation report" tool of the Web of Knowledge database. The information relating to the "sum of the times cited", "sum of times cited without self-citations", "citing articles", "citing articles without self-citations", "average citations per item", and "h-index" were noted down.

VOSviewer is primarily intended to be used for analysing bibliometric networks. The program can, for instance, be used to create maps of publications, authors, or journals based on a co-citation network and also to create maps of keywords based on a co-occurrence network. VOSviewer (version 1.5.4) (http://www.vosviewer.com/), a freely available computer program is used for constructing distance-based maps based on co-occurrence data. VOSviewer has been written in the Java programming language and runs on most hardware and operating system platforms (van Eck and Waltman 2010).

Figure 1 Label view of VOSviewer of bibliographical coupling of authors in Ecology

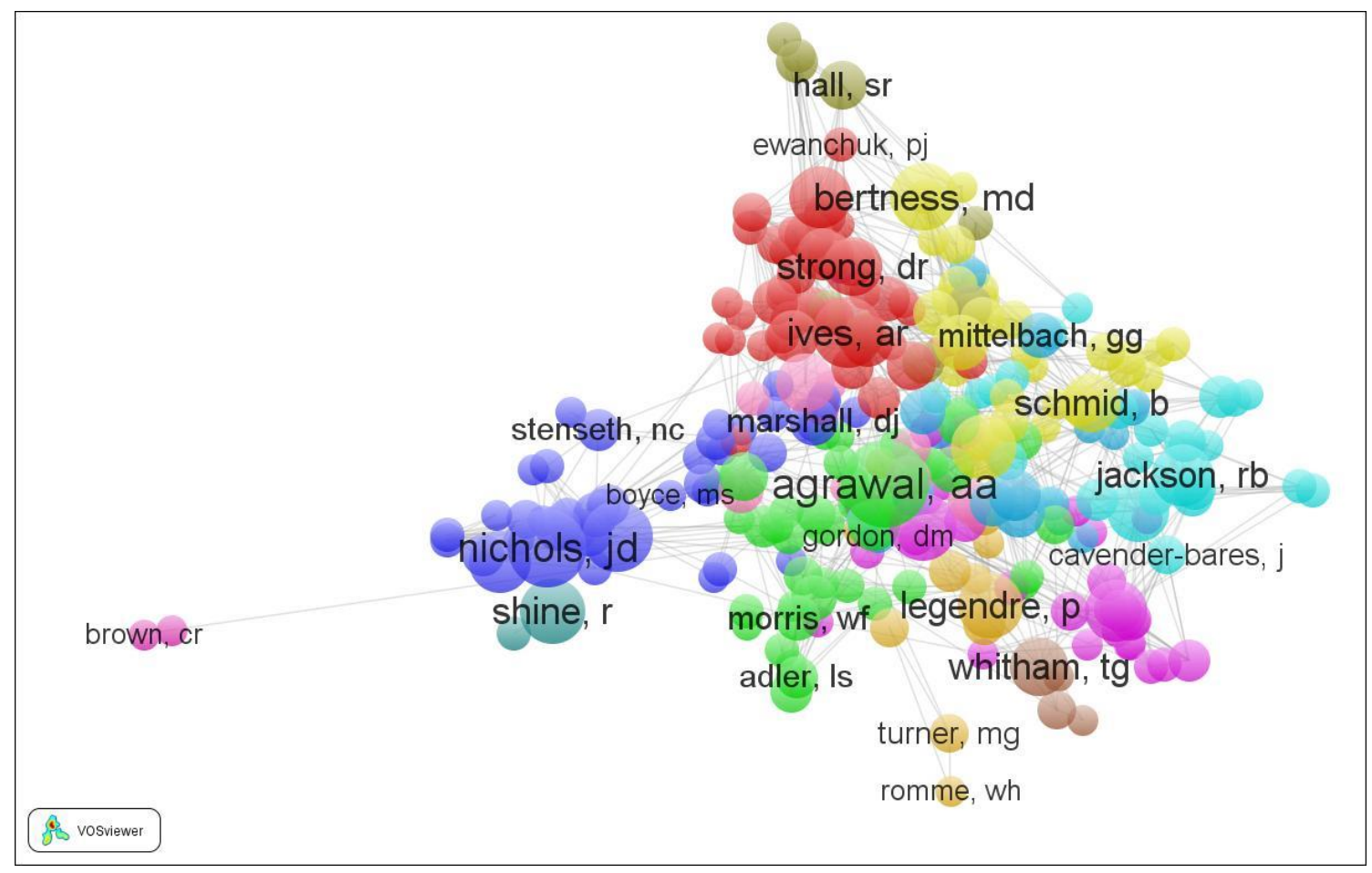

For the study period, we employed VOSviewer to analyse the publications in the journal (Figure 1). With the fractional counting method, documents with more than five authors were selected. Of the 7,253 authors, 278 met the threshold. For each of the 278 authors, the number of bibliographic coupling links was calculated. The authors with the largest number of links (277 items) were connected in fourteen clusters with different colours. In the label view, 277 items are indicated both by their label and by a circle. For each item, the font size of the item's label and the size of the item's circle vary depending on the weight of the item. If items have been assigned to clusters, the colour of the circle of an item can be determined by the cluster to which the item belongs. This clearly shows the most prolific authors, among them A.A. Agrawal, J.D. Nichols, and A.R. Ives.

\subsection{Organisation-wise distribution}

There were 1,483 organisations or institutions involved in publications in the journal during 2003-2012. Of the 1,483 institutions, $816(55.02 \%)$ contributed single-institutional publications and the remaining $667(44.98 \%)$ contributed interinstitutionally collaborated publications. The performance of the top fifteen most productive institutions was examined and 
is presented in Table 5. Of the top fifteen most productive institutions, fourteen are in the USA and one in Canada. Universities remain the dominant contributors in Ecology.

Table 5 Organisation-wise distribution of Ecology, 2003-2012 (first 15 countries)

\begin{tabular}{lccc}
\hline \multicolumn{1}{c}{ Organisations } & Country & No. of Papers & \% of $\mathbf{3 3 5 9}$ \\
\hline University Calif Davis & USA & 182 & 5.41 \\
University Calif Santa Barbara & USA & 103 & 3.06 \\
University Calif Berkeley & USA & 92 & 3.06 \\
US Geol Survey & USA & 92 & 2.73 \\
Duke University & USA & 92 & 2.73 \\
University Wisconsin & USA & 83 & 2.47 \\
University Florida & USA & 77 & 2.29 \\
Colorado State University & USA & 76 & 2.26 \\
Cornell University & USA & 76 & 2.26 \\
University Minnesota & USA & 75 & 2.23 \\
University Washington & USA & 71 & 2.11 \\
Oregon State University & USA & 69 & 2.05 \\
University British Columbia & USA & 58 & 1.78 \\
University Montana & USA & 60 & 1.75 \\
University Calif Santa Cruz & 59 & \\
\hline
\end{tabular}

VOSviewer constructs a map based on a co-occurrence matrix. The construction of a map is a process that consists of three steps. In the first step, a similarity matrix is calculated based on the co-occurrence matrix. In the second step, a map is constructed by applying the VOS mapping technique to the similarity matrix. And finally, in the third step, the map is translated, rotated, and reflected (van Eck and Waltman 2010).

Figure 2 Label view of VOSviewer of bibliographical coupling of organisations in Ecology

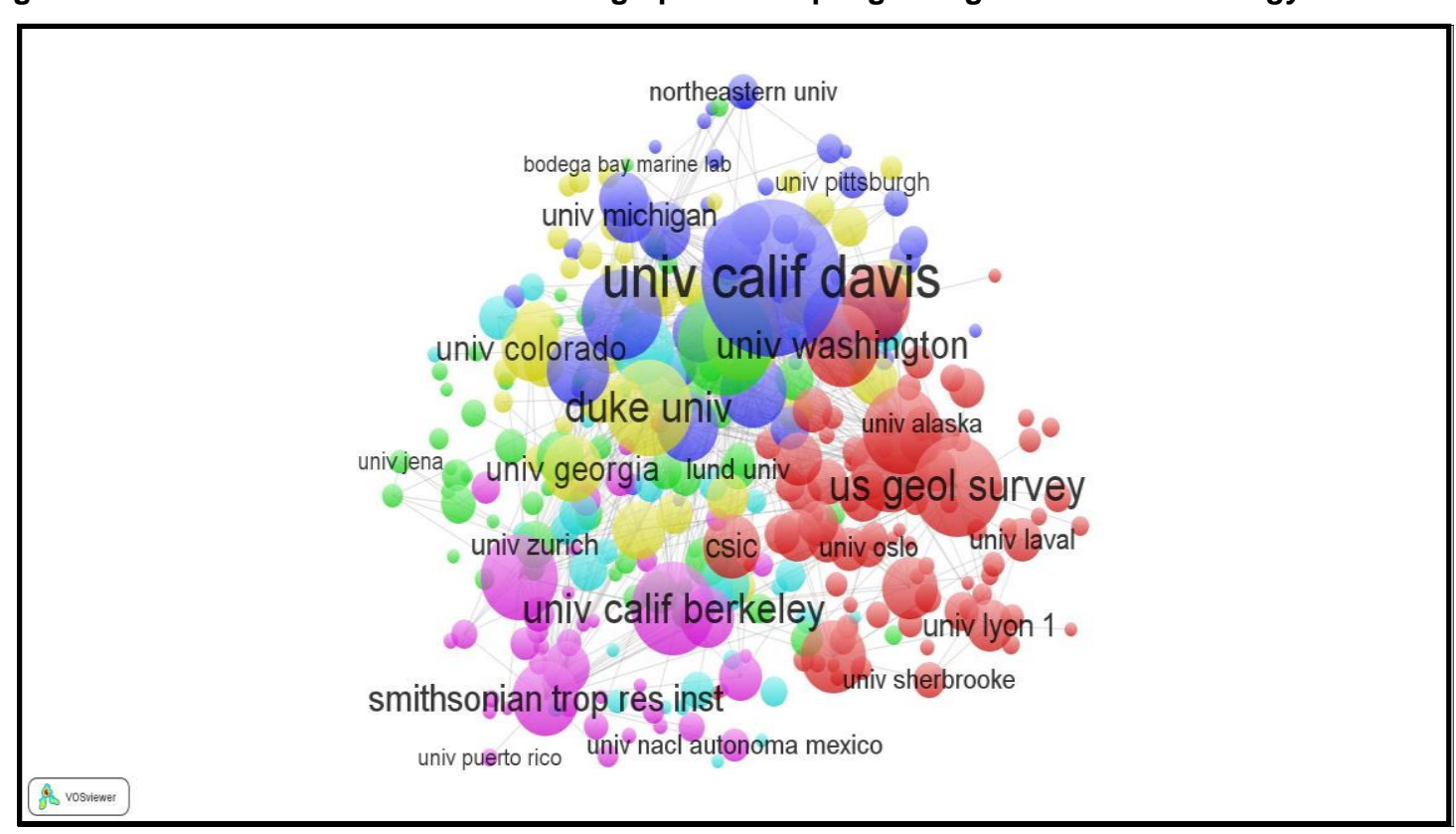


The output file from VOSviewer (Figure 2) is a map based on a network of bibliographic couplings according to organisation With the fractional counting method, more than five documents of organisations were selected. Of the 1,483 organisations, 314 items met the threshold. For each of the 314 organisations, the number of bibliographic coupling links was calculated. The organisations with the largest number of links (314 items) were connected in thirteen clusters with colours (blue, green and red). These clusters are collaboration clusters in terms of the number of publications produced jointly. In the label view, 314 items are indicated by a label and by a circle. In the figure, different colour-coded regions show different clusters. Colours indicate the clusters to which an organisation is assigned. The thirteen clusters correspond to 314 organisations which produced more than five documents in the research period. Table 6 shows the details of the thirteen collaboration clusters and the colour coding details.

Table 6 Collaboration clusters in organisation

\begin{tabular}{|c|c|c|c|c|}
\hline Cluster & $\begin{array}{l}\text { Cluster } \\
\text { Colours }\end{array}$ & $\begin{array}{l}\text { No. of Items (No. of } \\
\text { organisations) }\end{array}$ & No. of documents & Cluster top most organisation \\
\hline 1 & & 55 & 629 & CNRS \\
\hline 2 & & 38 & 603 & University of British Columbia \\
\hline 3 & & 37 & 706 & University of Calif Davis \\
\hline 4 & & 35 & 767 & US Geological Survey \\
\hline 5 & & 31 & 474 & Yale University \\
\hline 6 & & 22 & 352 & University of Illinois \\
\hline 7 & & 18 & 250 & University of Wisconsin \\
\hline 8 & & 17 & 339 & Cornell University \\
\hline 9 & & 15 & 380 & University of Florida \\
\hline 10 & & 13 & 375 & Duke University \\
\hline 11 & & 12 & 229 & University Calif Santa Cruz \\
\hline 12 & & 11 & 116 & Lund University \\
\hline 13 & & 10 & 185 & University Toronto \\
\hline
\end{tabular}

VOS mapping technique is to minimise a weighted sum of the squared Euclidean distances between all pairs of items. The higher the similarity between two items, the higher the weight of their squared distance in the summation. The distance based measurement stratifies different clusters here based on the publication number occurring as a pair. The map clearly depicts the most prolific organisations.

\subsection{Geographical distribution of contributors}

Country-wise distribution of the authors (Table 7) indicates that most of the papers were contributed by USA, followed by Canada and England. Being the originating country, and host to more scientific institutions, it is not surprising that the USA was the top contributing country.

Table 7 Country-wise distribution of Ecology during 2003-2012

\begin{tabular}{lccc}
\hline \multicolumn{1}{c}{ Countries } & No. of Publications & Percentage & Rank \\
\hline USA & 2188 & 65.13 & 1 \\
Canada & 389 & 11.58 & 2 \\
England & 246 & 7.32 & 3 \\
Australia & 224 & 6.66 & 4 \\
France & 173 & 5.15 & 5 \\
Germany & 151 & 4.49 & 6 \\
Sweden & 134 & 3.98 & 7 \\
Netherlands & 131 & 3.9 & 8 \\
Switzerland & 122 & 3.63 & 9 \\
Spain & 106 & 3.15 & 10 \\
New Zealand & 91 & 2.70 & 11 \\
Norway & 72 & 2.14 & 12 \\
Scotland & 68 & 2.02 & 13 \\
\hline
\end{tabular}


Table 7 Country-wise distribution of Ecology during 2003-2012

\begin{tabular}{lccc}
\hline \multicolumn{1}{c}{ Countries } & No. of Publications & Percentage & Rank \\
\hline Finland & 61 & 1.81 & 14 \\
Panama & 47 & 1.39 & 15 \\
Japan & 44 & 1.31 & 16 \\
Brazil & 39 & 1.16 & 17 \\
South Africa & 37 & 1.10 & 18 \\
Argentina & 36 & 1.07 & 19 \\
Mexico & 36 & 1.07 & 19 \\
Denmark & 34 & 1.01 & 20 \\
Peoples R China & 34 & 1.01 & 20 \\
Belgium & 32 & 0.95 & 21 \\
Israel & 28 & 0.83 & 22 \\
Chile & 21 & 0.62 & 23 \\
Italy & 21 & 0.62 & 24 \\
Ireland & 19 & 0.56 & 25 \\
Wales & 17 & 0.50 & 26 \\
Czech Republic & 16 & 0.47 & 27 \\
Portugal & 15 & 0.44 & 28 \\
India & 14 & 0.41 & 29 \\
\hline
\end{tabular}

\subsection{Most highly cited papers of journal Ecology in 2003}

The bibliographic details of highly-cited papers for the year of commencement of the study, 2003, for Ecology are listed in Appendix 1. Fourteen of the most cited papers of 2003 originated from the USA (seven), followed by Canada (three), New Zealand (two), Sweden (one) and South Africa (one). The highest cited papers from South Africa for the study period are provided in Appendix 2.

\subsection{Growth of cited references in the journal Ecology}

Citations and references are the backbone of any article. Supporting the content of a manuscript with proper references plays an important role in its reliability. The annual distribution of cited references (Table 8) reveals that the highest cited references were in the year 2010, followed by 2008, while the lowest were in the year 2011.

Table 8 Distribution of cited references and Impact Factors in journal Ecology, 2003-2012

\begin{tabular}{cccccc}
\hline Year & $\begin{array}{c}\text { No of } \\
\text { Articles }\end{array}$ & $\begin{array}{c}\text { No of } \\
\text { Cited References }\end{array}$ & $\begin{array}{c}\text { Cumulative } \\
\text { No. of Cited References }\end{array}$ & $\begin{array}{c}\text { Impact } \\
\text { Factor }\end{array}$ \\
\hline 2003 & 327 & 17338 & 17338 & 10.55 & $*$ \\
2004 & 348 & 17013 & 34351 & 10.35 & 4.104 \\
2005 & 357 & 16687 & 51038 & 10.15 & 4.506 \\
2006 & 346 & 16986 & 68024 & 10.33 & 4.782 \\
2007 & 336 & 15747 & 83771 & 9.58 & 4.822 \\
2008 & 374 & 18750 & 102521 & 11.41 & 4.874 \\
2009 & 352 & 17382 & 119903 & 10.57 & 4.411 \\
2010 & 387 & 18881 & 138784 & 11.49 & 5.073 \\
2011 & 240 & 10577 & 149361 & 6.43 & 4.849 \\
2012 & 292 & 15008 & 164369 & 9.13 & 5.175 \\
Total & 3359 & 164369 & & 100 & \\
\hline
\end{tabular}

* 2003 IF was not available in Web of Science

Impact Factor (IF) is calculated and published in the Journal Citation Reports brought out by Thomson Reuters, providing a practical tool for evaluating scientific production. The journal impact factor is a measure of the frequency with which the "average article" in a journal has been cited in a particular year. It measures the number of citations given in a 
journal in the previous year to the citable items published in the two years prior, divided by citable items published in the two prior years (Garfield 1976). For example, the IF calculation for the journal Ecology in 2012 is given below:

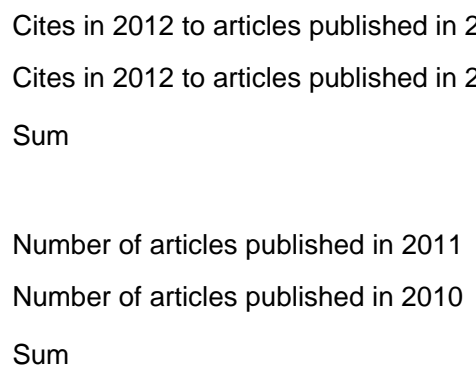

Sum

Calculation

2012 IF for the journal Ecology

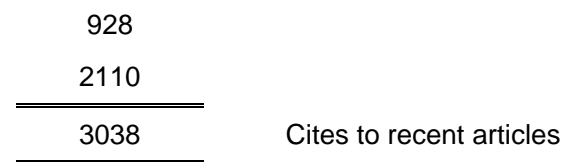

\begin{tabular}{l}
230 \\
357 \\
\hline \hline 587
\end{tabular}$\quad$ Number of recent articles

$\frac{\text { Cites to recent articles }}{\text { Number of recent articles }}=\frac{3038}{\frac{587}{\mathbf{5 . 1 7 5}}}$

The IF for the study period was sourced from Web of Knowledge in the Journal Citation Reports (JCR) from 2004 to 2012 (Table 8).

\section{Results and discussion}

The total number of articles published in Ecology available in Web of Science was 3,359 for 2003-2012. The majority of papers appeared in the year 2010 (387 papers). The h-index of the most prolific author, A.A. Agrawal, with 22 papers, was found to be thirteen. The authorship pattern showed that most papers were multiple-authored (three to six authors) (1,783 papers, 53.08). This number may be compared to single-author papers (410 papers, $12.21 \%)$. In the distribution of articles according to country, the USA occupies the first place with 2,188 articles (65.13\%). The University of California at Davis contributed the most, ranking first according to institution, with 182 papers $(5.41 \%)$.

Though this study considered only one journal in the vast field of ecology for bibliometric studies, the journal Ecology is recognised as a leading journal, given its high impact factor and popularity. It can be argued that the patterns discerned from this study therefore might well be reflective of the emerging trends in the discipline of ecology. It will be interesting to classify the broad issues addressed in the journal and study their trends over a period of time.

\section{Conclusion}

The present work has taken up a detailed analysis of the journal Ecology over a ten-year period (2003-2012). The work provides a reasonable glimpse of the field of ecology, using a reputed journal indicating the direction in which the discipline is going. It is heartening to note that in this scientific discipline, researchers from across the world have shown a strong inclination towards collaborative research which is significant in the present-day context. It will be interesting to replicate this work in a few years from now to observe the changes in the discipline.

\section{References}

Ajiferuke, I., Burrel, Q. and Tague, J. 1988. Collaborative coefficient: a single measure of the degrees of collaboration in research. Scientometrics, 14(5-6): 421-433.

Aswathy, S. and Gopikuttan, A. 2012. Journal of Spacecraft and Rockets: a Scientometric analsyis. SRELS Journal of Information Management, 49: 671-682.

Egghe, L. 1988. Methodological aspects of bibliometrics. Library science with a slant to documentation and information studies, 25(3): 179-191.

Mohamed, E.S., Nagarajan, M., and Jothi, S. 2011. Authorship trend and collaborative research in agricultural extension. Pearl: a Journal of Library and Information Science, 5(1): 42-46.

Garfield, E. 1976. Characteristics of highly cited publications in the engineering sciences. Current Contents, $12: 5-10$.

Hirsch, J.E. 2005. An index to quantify an individual's scientific research output. Proceedings of the National Academy of Sciences of the United States of America, 102 (46): 16569-16572.

Liu, T., Kong, H. and Duan, J. 2011. The analysis of Chinese ecological academic journals. Acta Ecologica Sinica, 31(10): 2924-2931.

Lotka, A.J. 1926. The frequency distribution of scientific productivity. Journal of the Washington Academy of Science, 16: 317-323.

Mahapatra, M. 1985. On the validity of the theory of exponential growth of scientific literature. 15th IASLIC conference proceedings. Bangalore: IASLIC, 61-70.

Narang, A. and Kumar, A. 2010. A bibliometric study of Indian Journal of Pure and Applied Mathematics. SRELS Journal of Information Management, 47(1): 31-39.

Pao, M.L. 1985. Lotka's Law: a testing procedure. Information Processing and Management, 21(4): 305-320. 
Pritchard, A. 1969. Statistical bibliography or bibliometics? Journal of Documentation, 25: 348-349.

Prozesky, H. and Boshoff, N. 2012. Bibliometrics as a tool for measuring gender-specific research performance: an example from South African invasion ecology. Scientometrics, 90(2): 383-406.

Sevukan, R. and Sharma, J. 2008. Bibliometric analysis of research output of biotechnology faculties in some Indian central universities. DECIDOC Journal of Library and Information studies, 28(6): 11-20.

Thanuskodi, S. and Venkatalakshmi, V. 2010. The growth and development of research on ecology in India: a bibliometric study. Library Philosophy and Practice (e-journal). Paper 359. [Online]. http://digitalcommons.unl.edu/libphilprac/359.

van Eck, N. J., and Waltman, L. 2010. Software survey: VOSviewer, a computer program for bibliometric mapping. Scientometrics, 84(2): 523-538.

We are grateful to Mr. S. Prasad, French Institute of Pondicherry, Pondicherry for his valuable suggestions. We would like to thank the Editor of SAJLIS and two anonymous reviewers for their valuable and fruitful comments on the earlier version of the manuscript. 


\section{Appendix 1}

Bibliographic details of highly cited papers in the journal Ecology for the year 2003

\begin{tabular}{|c|c|c|c|}
\hline S. NO. & Title/Source (Ecology) from WoS in 2003 & $\begin{array}{l}\text { Times } \\
\text { Cited } \\
\text { (WoS) }\end{array}$ & $\begin{array}{l}\text { Country of } \\
\text { origin of } \\
\text { first author }\end{array}$ \\
\hline 1 & $\begin{array}{l}\text { Energy, water, and broad-scale geographic patterns of species richness. By } \\
\text { Hawkins, BA; Field, R; Cornell, HV; et al. Volume: } 84 \text { (12): } 3105-3117\end{array}$ & 730 & USA \\
\hline 2 & $\begin{array}{l}\text { A review of trait-mediated indirect interactions in ecological communities. By Werner, } \\
\text { EE; Peacor, SD. Volume: } 84 \text { (5): 1083-1100 }\end{array}$ & 604 & USA \\
\hline 3 & $\begin{array}{l}\text { Confronting multicollinearity in ecological multiple regression. By Graham, MH. } \\
\text { Volume: } 84(11): 2809-2815\end{array}$ & 550 & USA \\
\hline 4 & $\begin{array}{l}\text { Canonical analysis of principal coordinates: A useful method of constrained } \\
\text { ordination for ecology. By Anderson, MJ; Willis, TJ. Volume: } 84 \text { (2): } 511-525\end{array}$ & 508 & $\begin{array}{l}\text { New } \\
\text { Zealand }\end{array}$ \\
\hline 5 & $\begin{array}{l}\text { Propagule dispersal in marine and terrestrial environments: A community } \\
\text { perspective. By Kinlan, BP; Gaines, SD. Volume: } 84 \text { (8): 2007-2020 }\end{array}$ & 403 & USA \\
\hline 6 & $\begin{array}{l}\text { Estimating site occupancy, colonization, and local extinction when a species is } \\
\text { detected imperfectly. By MacKenzie, DI; Nichols, JD; Hines, JE; et al. Volume: } 84 \\
\text { (8): } 2200-2207\end{array}$ & 401 & $\begin{array}{l}\text { New } \\
\text { Zealand }\end{array}$ \\
\hline 7 & $\begin{array}{l}\text { Variation in plant response to native and exotic arbuscular mycorrhizal fungi. By } \\
\text { Klironomos, JN. Volume: } 84(9): 2292-2301\end{array}$ & 360 & Canada \\
\hline 8 & $\begin{array}{l}\text { Estimating abundance from repeated presence-absence data or point counts. By } \\
\text { Royle, JA; Nichols, JD. Volume: } 84 \text { (3): } 777-790\end{array}$ & 288 & USA \\
\hline 9 & $\begin{array}{l}\text { Community and ecosystem genetics: A consequence of the extended phenotype. By } \\
\text { Whitham, TG; Young, WP; Martinsen, GD; et al. Volume: } 84 \text { (3): 559-573 }\end{array}$ & 286 & USA \\
\hline 10 & $\begin{array}{l}\text { Herbivore-mediated linkages between aboveground and belowground communities. } \\
\text { By Bardgett, RD; Wardle, DA. Volume: } 84 \text { (9): 2258-2268 }\end{array}$ & 281 & Sweden \\
\hline 11 & $\begin{array}{l}\text { Plant diversity, soil microbial communities, and ecosystem function: Are there any } \\
\text { links? By Zak, DR; Holmes, WE; White, DC; et al. Volume: } 84 \text { (8): 2042-2050 }\end{array}$ & 246 & USA \\
\hline 12 & $\begin{array}{l}\text { Meta-analysis of cod-shrimp interactions reveals top-down control in oceanic food } \\
\text { webs. By Worm, B; Myers, RA. Volume: } 84 \text { (1): 162-173 }\end{array}$ & 240 & Canada \\
\hline 13 & $\begin{array}{l}\text { Piecewise regression: A tool for identifying ecological thresholds. By Toms, JD; } \\
\text { Lesperance, ML. Volume: } 84(8): 2034-2041\end{array}$ & 230 & Canada \\
\hline 14 & $\begin{array}{l}\text { Effects of fire and herbivory on the stability of savanna ecosystems. By van } \\
\text { Langevelde, F; van de Vijver, CADM; Kumar, L; et al. Volume: } 84 \text { (2): } 337-350\end{array}$ & 217 & $\begin{array}{l}\text { South } \\
\text { Africa }\end{array}$ \\
\hline
\end{tabular}




\section{Appendix 2}

\begin{tabular}{|c|c|}
\hline S.NO. & Title/Source \\
\hline 1 & $\begin{array}{l}\text { Effects of fire and herbivory on the stability of savanna ecosystems. By: van Langevelde, F; van } \\
\text { Vijver, CADM; Kumar, L; et al. Ecology, } 84 \text { (2): 337-350, Feb. } 2003\end{array}$ \\
\hline 2 & $\begin{array}{l}\text { Pollination success in a deceptive orchid is enhanced by co-occurring rewarding magnet plants. } \\
\text { Johnson, SD; Peter, Cl; Nilsson, LA; et al. Ecology, } 84 \text { (11): 2919-2927, Nov. } 2003\end{array}$ \\
\hline 3 & $\begin{array}{l}\text { Interactions between environment, species traits, and human uses describe patterns of plant } \\
\text { invasions. By: Thuiller, Wilfried; Richardson, David M.; Rouget, Mathieu; et al. Ecology, } 87 \text { (7): } \\
\text { 1755-1769, Jul. } 2006\end{array}$ \\
\hline
\end{tabular}

4 Effects of four decades of fire manipulation on woody vegetation structure in savanna By: Higgins, Steven I.; Bond, William J.; February, Edmund C.; et al. Ecology, 88 (5): 1119-1125, May 2007

5 Habitat loss, trophic collapse, and the decline of ecosystem services By: Dobson, Andrew; Lodge, David; Alder, Jackie; et al. Ecology. 87 (8):1915-1924, Aug. 2006

$6 \quad$ Relating plant traits and species distributions along bioclimatic gradients for 88 Leucadendron taxa By: Thuiller, W; Lavorel, S; Midgley, G; et al. Ecology, 85 (6): 1688-1699, Jun. 2004

7 Surface-water constraints on herbivore foraging in the Kruger National Park, South Africa By: Redfern, JV; Grant, R; Biggs, H; et al. Ecology, 84 (8): 2092-2107, Aug. 2003

8 Microbial nitrogen limitation increases decomposition By: Craine, Joseph M.; Morrow, Carl; Fierer, Noah. Ecology, 88 (8): 2105-2113, Aug. 2007

9 Dark, bitter-tasting nectar functions as a filter of flower visitors in a bird-pollinated plant By: Johnson, Steven D.; Hargreaves, Anna L.; Brown, Mark. Ecology, 87 (11): 2709-2716, Nov. 2006

Phenotypic variation of larks along an aridity gradient: Are desert birds more flexible? By: Tieleman, Bl; Williams, JB; Buschur, ME; et al. Ecology, 84 (7): 1800-1815, Jul. 2003

Collapse of a pollination web in small conservation areas By: Pauw, Anton. Ecology, 88 (7): 17591769, Jul. 2007

Environmental constraints on a global relationship among leaf and root traits of grasses By: Craine, JM; Lee, WG; Bond, WJ; et al. Ecology, 86 (1): 12-19, Jan. 2005 prey web By: Owen-Smith, Norman; Mills, M. G. L. Ecology, 89 (4): 1120-1133, Apr. 2008 Pimm, SL; et al. Ecology, 86 (3): 655-666, Mar. 2005 stable states By: Staver, A. Carla; Archibald, Sally; Levin, Simon. Ecology, 92 (5): 1063-1072, May 2011

A mutualism with a native membracid facilitates pollinator displacement by Argentine ants By: Lach, Lori. Ecology, 88 (8): 1994-2004, Aug. 2007 Published: AUG 2007 

animal location time series data By: Polansky, Leo; Wittemyer, George; Cross, Paul C.; et al. Ecology, 91 (5): 1506-1518, May 2010 upwelling By: Cole, Victoria J.; McQuaid, Christopher D. Ecology, 91 (12): 3549-3562, Dec. 2010

Do novel genotypes drive the success of an invasive bark beetle-fungus complex? Implications for potential reinvasion By: Lu, Min; Wingfield, Michael J.; Gillette, Nancy; et al. Ecology, 92 (11): 20132019, Nov. 2011

Dynamics and management of infectious disease in colonizing populations By: Bar-David, S; Lloyd-Smith, JO; Getz, WM. Ecology, 87 (5): 1215-1224, May 2006 486, Feb. 2011

Native pollen thieves reduce the reproductive success of a hermaphroditic plant, Aloe maculate By: Hargreaves, Anna L.; Harder, Lawrence D.; Johnson, Steven D. Ecology, 91 (6): 1693-1703, Jun. 2010 approach By: Boettiger, Alistair N.; Wittemyer, George; Starfield, Richard; et al. Ecology, 92 (8): 1648-1657, Aug. 2011

Defoliation synchronizes aboveground growth of co-occurring C-4 grass species. By: Swemmer, Anthony M.; Knapp, Alan K. Ecology, 89 (10): 2860-2867, Oct. 2008 2310-2315, Dec. 2011 